\title{
Improving energy performance power station of ship with integrated electric propulsion
}

\author{
Andrey Dar'enkov ${ }^{1}$, Ivan Samoyavchev ${ }^{1}$, Oleg Khvatov ${ }^{2}$, Valeriy Sugakov ${ }^{2}$ \\ ${ }^{1}$ Nizhny Novgorod State Technical University n.a. R.E. Alekseev, Institute of Electric Power Engineering, 603950 Nizhny Novgorod, Russia \\ ${ }^{2}$ Volga state university of water transport, Electromechanical Faculty, 603950 Nizhny Novgorod, Russia
}

\begin{abstract}
The article presents the method of calculating the power plant fuel consumption on the basis of dieselgenerating installation (DGI) with variable speed for ships with integrated electric propulsion. Application DGI with variable speed allows saving fuel and therefore reducing harmful emissions into the atmosphere. In the paper calculated the fuel efficiency of unified power station on the basis of a variable speed DGI power of $1000 \mathrm{~kW}$.
\end{abstract}

\section{Introduction}

On water transport are increasingly using integrated electric propulsion. This propulsion motors (PM) can be supplied together with other consumers from a unified power station (UPS). Application UPS simplifies maintenance and improves the reliability of the energy system of autonomous object by reducing the total number of system elements. The primary engine UPS widely used internal combustion engines (ICE).

As a rule, UPS are based on diesel DGI of constant rotation speed rotation. The electric power station gain in performance is possible due to variable speed rotation of DGI application. Fuel saving in this case is performed by setting for each load power value the optimal ICE shaft rotation frequency corresponding to the minimal fuelconsumption rate $[1,2]$.

The UPS - DGI with variable speed rotation is a relatively new technical trend in small power. Research this systems carried out several foreign companies such as Fubag, Honda, Hyundai, Kypor, ABB, Wartsila etc. In Russia research carried out - JSC "R\&D Center for power engineering" (Moscow), JSC "ZVEZDA" (St. Petersburg), JSC "Sigma" (Kovrov), VSUWT and NNSTU (N.Novgorod).

The use of UPS - DGI can reduce the absolute and relative Fuel consumption and ensure optimal thermal operation of DGI, improve service life and reduce the amount of harmful emissions into the atmosphere.

\section{Fuel saving calculation of UPS with variable speed rotation}

Determination the relative and absolute indexes of fuel consumption of UPS with a variable frequency of rotation DGI has been carried out as shown by UPS ship with electric propulsion [4]. The calculation takes into account the energy loss of each element of the power structure of the UPS (fig. 1) when the load power changing over the entire range. On fig. 1 energy diagram, where $\mathrm{G}$ absolute fuel consumption rate, $\mathrm{P}_{\mathrm{m}}$ - power of DGI, $\mathrm{P}_{\mathrm{SG}}$ power of $\mathrm{SG}, \mathrm{P}_{\mathrm{FC}}-$ power of frequency converter, $\mathrm{P}_{\mathrm{T}}-$ power of transformer, $\Delta \mathrm{P}_{\mathrm{m}}, \Delta \mathrm{P}_{\mathrm{SG}}, \Delta \mathrm{P}_{\mathrm{FC}}, \Delta \mathrm{P}_{\mathrm{T}}$ - power loss.

It should be noted that the change load power in UPS causes a change speed shaft of DGI [3]. When calculating UPS efficiency it is taken into account those electrical equipment elements, comprised in UPS with a variable frequency of rotation DGI (synchronous generator (SG), $\mathrm{PM}$, transformer $(\mathrm{T})$, frequency converter $(\mathrm{FC})$ ) operate at variable frequency and voltage range. The ICE fuel consumption rate is determined according to the multivariate ICE characteristic [1].

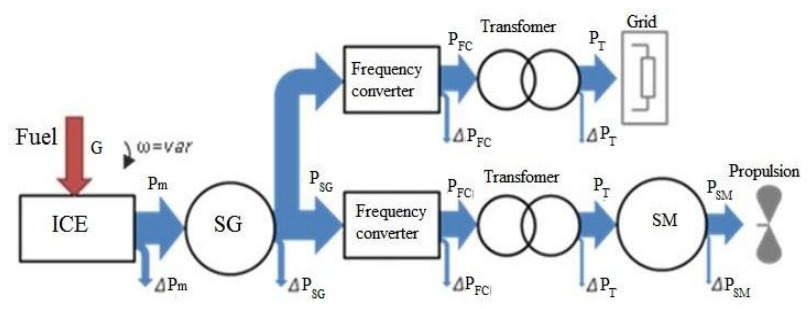

Figure 1. Energy diagram of power circuit UPS with variable speed DGI.

\section{UPS elements efficiency calculation}

To calculate the efficiency of the UPS are used depending on the efficiency of the voltage frequency for each power element of UPS.

\subsection{Efficiency of synchronous machine}

The synchronous machine efficiency (SM) is determined through the following equations 


$$
\begin{aligned}
& \eta_{S M}=1-p_{\Sigma} / P_{1}, \\
& p_{\Sigma}=p_{i}+p_{b}+p_{c}+p_{a d d}+p_{m e c h}, \\
& p_{a d d}=0,005 P_{1}\left(\frac{I_{1}}{I_{1 n}}\right), \\
& p_{i}=p_{1,0 / 50}(f / 50)^{\beta} K\left(B_{s 1}^{2} m_{s 1}+B_{s 2}^{2} m_{s 2}\right), \\
& p_{b}=U_{b} I_{f}, \\
& p_{c}=m_{1} I_{1}^{2} r_{1} m_{t}+m_{2} I_{2}^{2} r_{2} m_{t}, \\
& p_{\text {mech }}=8\left(n_{1} / 1000\right)^{2}\left(D_{1} / 100\right)^{3} .
\end{aligned}
$$

In (1) are used $\eta_{\mathrm{SM}}-$ synchronous machine efficiency $P_{1}-$ power consumption, $p_{\Sigma}-$ total losses in a machine, $p_{\mathrm{i}}$ - iron losses, $p_{\mathrm{b}}-$ brush friction losses, $p_{\mathrm{c}}$ - copper losses, $p_{\text {add }}-$ additional losses, $p_{\text {mech }}-$ mechanical losses, $p_{1,0 / 50}-$ specific magnetic losses, $f$ - stator voltage frequency, $B_{\mathrm{s} 1}$, $B_{\mathrm{s} 2}$ - induction corresponding to stator finger and lamination, $K$ - correcting coefficient, $\beta$ - coefficient, considering the steel losses dependency on the magnetization ratio; $m_{s 1}$ - stator finger mass; $m_{s 2}$ stator lamination mass, $r_{1}$ - effective resistance of stator coil phase, $m_{\mathrm{t}}-$ ratio considering the coil heat.

Fig 2 shows the efficiency dependencies on stator primary voltage frequency for a synchronous machine MCK1250-1500 $\left(P_{\mathrm{N}}=1000 \mathrm{~kW}, n=1500 \mathrm{~min}^{-1}\right)$. The dependencies correspond to load power $P_{1}=0,25 P_{\mathrm{N}}$; $0,5 P_{\mathrm{N}} ; 0,75 P_{\mathrm{N}} ; P_{\mathrm{N}}$.

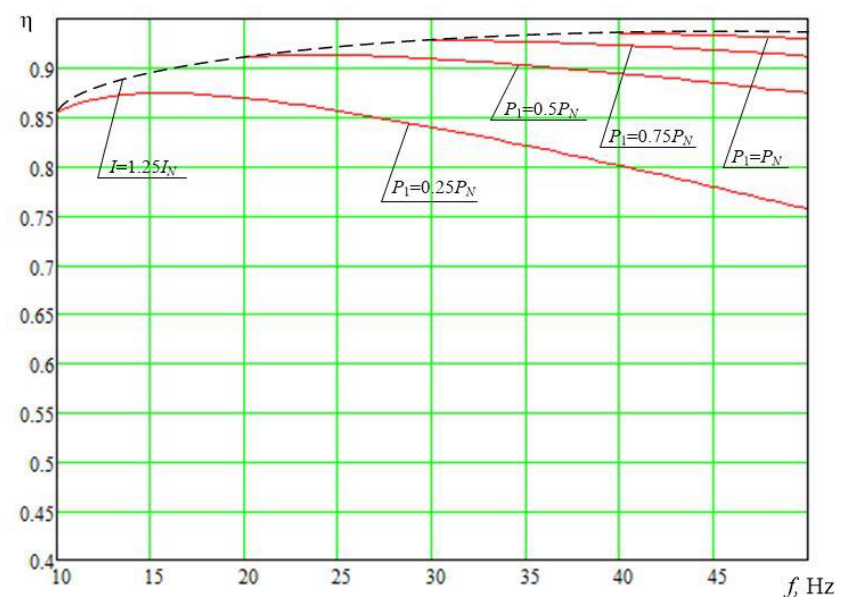

Figure 2. Dependency of MCK1250-1500 SM efficiency on frequency of power voltage at variable power $P_{1}$.

According to [1] synchronous machines of MCK series the operate duration at stator current $I=1,25 I_{\mathrm{N}}$ is not to exceed 0,5 h. Fig. 2 and the following ones the dotted line limits the area of currents control $I \leq 1,25 I_{\mathrm{N}}$.

\subsection{Efficiency of transformer}

The transformer efficiency is determined by mainly the following equations

$$
\begin{aligned}
& \eta_{T}=1-p_{\Sigma} / P_{1}, \\
& p_{\Sigma}=p_{w 1}+p_{i T}+p_{w 2}, \\
& p_{i T}=v^{\prime}(f / 50)^{\beta} B^{\alpha} G_{c}, \\
& p_{w 1}=m I_{1}^{2} r_{1} m_{t}, \\
& p_{w 2}=m I_{2}^{2} r_{2} m_{t} .
\end{aligned}
$$

In (2) the following notations are used $\eta_{T}-$ transformer efficiency; $p_{\Sigma}-$ total losses, $p_{\mathrm{w} 1}, p_{\mathrm{w} 2}-$ electrical losses ones in winding, $p_{\mathrm{iT}}-$ steel losses, $v^{\prime}$ specific steel losses $[1,5], G_{\mathrm{C}}$-core steel mass, $m-$ the transformer phase number, $m_{t}-$ coil heat ratio; $I_{1}, I_{2}, r_{1}, r_{2}$ - respectively currents and resistance values of primary and secondary transformer windings.

Fig. 3 shows dependencies of the efficiency of voltage frequency of transformer TC3M 1000-75.OM5.

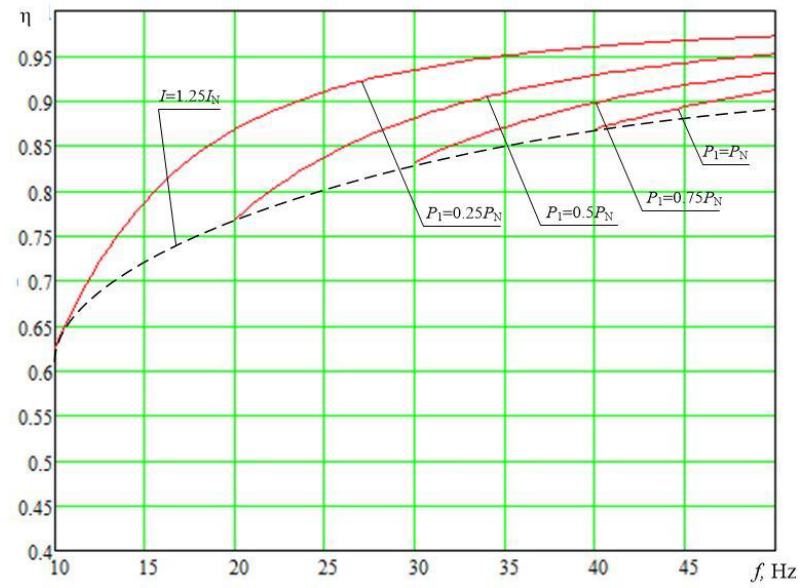

Figure 3. Dependency of transformer efficiency TC3M 1000-75.OM5 of supply voltage frequency.

\subsection{Efficiency of frequency converter}

Frequency converter (Fig. 4) efficiency as shown are calculated according to the following equations

$$
\begin{aligned}
& \eta_{F C}=\eta_{r e c} \eta_{p w c} \eta_{f 1} \eta_{i n v} \eta_{f 2}, \\
& \eta_{r e c}=\frac{P_{d}}{P_{d}+\Delta P_{r e c}}, \Delta P_{r e c}=\Delta P_{s e m}+\Delta P_{s u b}, \\
& \Delta P_{s e m}=\left(U_{T 0} I_{F a v}+r_{T} k_{\phi}^{2} I_{F a v}^{2}\right) \cdot 6, \\
& \Delta P_{L}=R_{L} I_{D}^{2}, \eta_{f 1}=\frac{P_{d}}{P_{d}+\Delta P_{L}}, \\
& \Delta P_{I G B T}=P_{D}+P_{S W}+P_{D F}, P_{D}=I_{c a v} U_{C E}\left(I_{c}\right), \\
& P_{S W}=E_{t s} f, P_{D F}=I_{F M} U_{F M} .
\end{aligned}
$$

In (3) are used $\eta_{F C}-$ efficiency of frequency converter, $\eta_{r e c}-$ efficiency of rectifier, $\eta_{p w c}$ - efficiency of pulsewidth converter, $\eta_{f 1,2}$ - efficiency of filter, $\eta_{i n v}-$ efficiency inverter, $P_{d}$ - active power at the rectifier outlets, $\Delta P_{\text {rec }}$ - rectifier losses, $P_{\text {sem }}$ - semi-conducting equipment devices losses, $\Delta P_{\text {sub }}-$ cooling system, system protection and control system losses, $\Delta . P_{F A V}-$ diode losses resulting from direct current flow $I_{F A V}, k_{\phi}$ - current form ratio, $r_{T}$ - differential resistance, $U_{T 0}$ - threshold voltage, $\Delta P_{L}$-filter inductance losses, $\Delta P_{I G B T}-$ IGBT 
losses, $P_{D}$ - dynamic in IGBT transistor losses, $P_{S W}$ static in IGBT transistor losses, $P_{D F}$ - built-in IGBT diode losses, $I_{C A V}-$ the average impulse current conductivity collector value, $U_{C E(I c)}$ - saturation voltage at the given collector current, $E_{t s}$ - total energy losses at the collector losses current together with block drive circuit , $I_{F M}-$ diode average current; $U_{F M}$ - diode voltage at current $I_{F M}$.

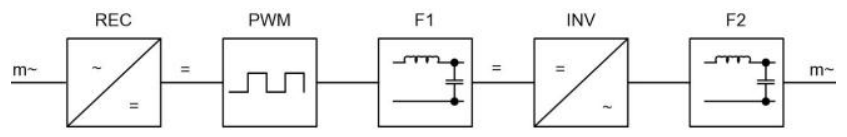

Figure 4. Flowchart of UPS frequency converter: rec - out-ofcontrol rectifier, PWM - pulse width converter, F1, F2 - filters, Inv - stand-alone inverter.

Fig. 5 shows the dependencies of the efficiency of voltage frequency for the frequency converter having the nominal power $1000 \mathrm{~kW}$.

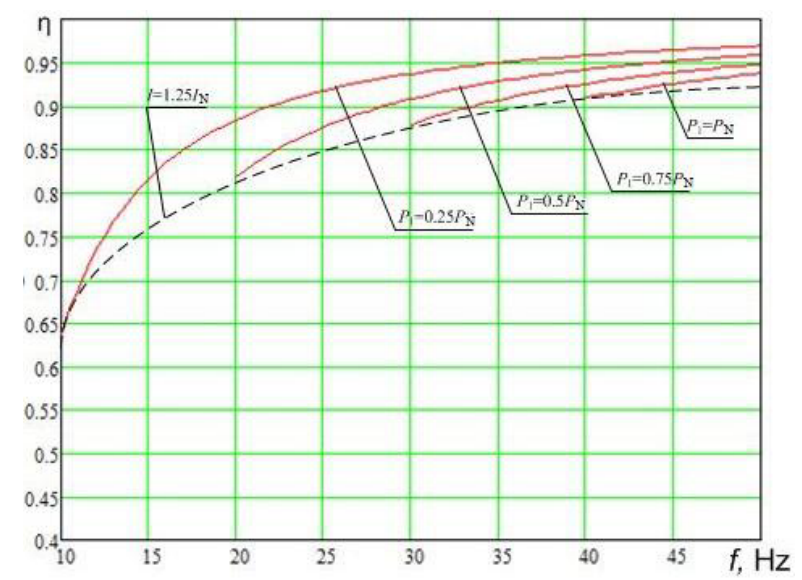

Figure 5. The dependence of the efficiency of the frequency converter power $1000 \mathrm{~kW}$ from the utility power frequency.

\section{UPS fuel economy estimate at load power «propulsion engine»}

Installed power of the SM is the sum propulsion power and the onboard ship power (fig. 1).

Fuel consumption of ICE is calculated in a range of screw-propeller (SP) speeds from 75 to $300 \mathrm{~min}^{-1}$ in increments of $25 \mathrm{~min}^{-1}$.

To determine the ICE fuel consumption is used multivariable characteristic $[6,7]$. ICE with a nominal speed of $400 \mathrm{~min}^{-1}$ and a power $1100 \mathrm{~kW}$ is selected to perform the calculations [1].

The shat moment on the SP is determined according to the equation

$$
M=K \rho n^{2} D_{p}^{5}
$$

where $K$-torque coefficient SP, $\rho$ - medium density, $n-$ frequency of rotation $\mathrm{SP}, D_{\mathrm{p}}$-diameter SP.

The supply voltage frequency $\mathrm{SM}$ is determined through the expression

$$
f=f_{0} \frac{n_{S P}}{n_{S P_{-} 0}}
$$

where $f_{0}$ - nominal frequency $\mathrm{SM}, n_{\mathrm{SP}}$ - current frequency $\mathrm{SP}, n_{\mathrm{SP} \_}-$nominal frequency of DGI.

Determine the efficiency of the FC, T, SM for each specified speed of SP.

The power SM is determined through the following equation

$$
P_{S M}=P_{S P} /\left(\eta_{S M} \cdot \eta_{F C} \cdot \eta_{T}\right) .
$$

There have been obtained the graphs of specific fuel consumption rate $\left(G_{e}\right)$ on the SP rotation $(n)$ for the two UPS modes with the controlled and uncontrolled DGI (Fig. 6-9). The obtained figures show UPS with the controlled rotation frequency of DGI as compared to UPS without frequency control of DGI.

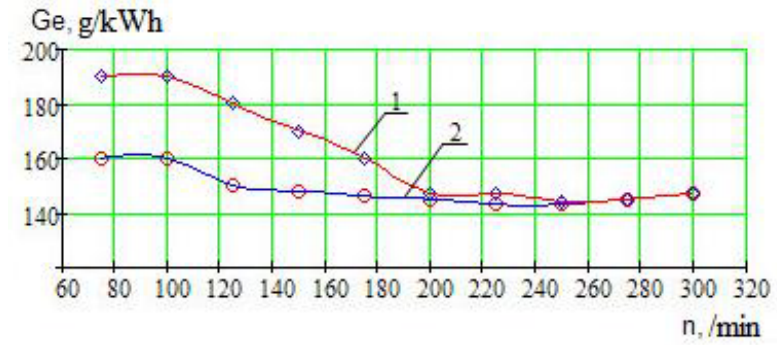

Figure 6. ICE fuel consumption rate of UPS power $1000 \mathrm{~kW}$ : 1 -without regulation of speed DGI, 2 - with frequency regulation of speed DGI.

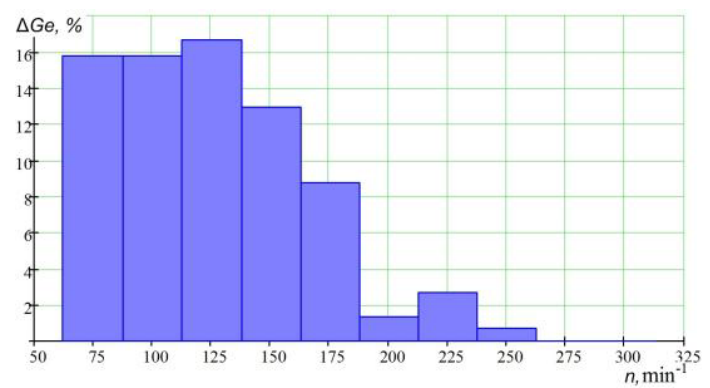

Figure 7. ICE fuel consumption rate UPS powered by $1000 \mathrm{~kW}$

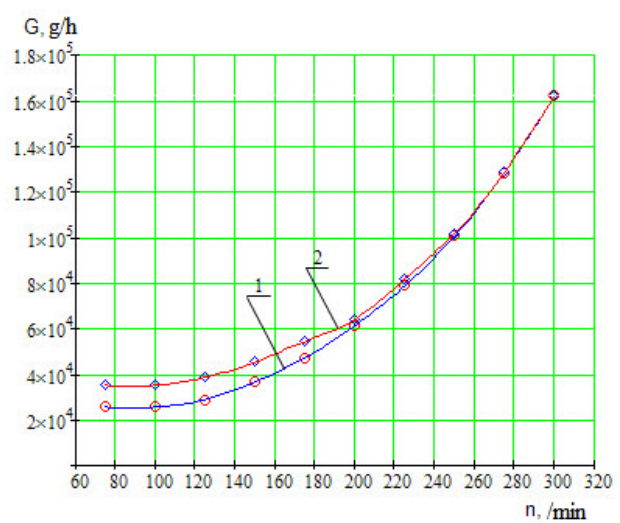

Figure 8. ICE absolute fuel consumption of UPS powered by $1000 \mathrm{~kW}: 1$ - with the regulation of frequency DGI; 2 without the frequency regulation of DGI. 


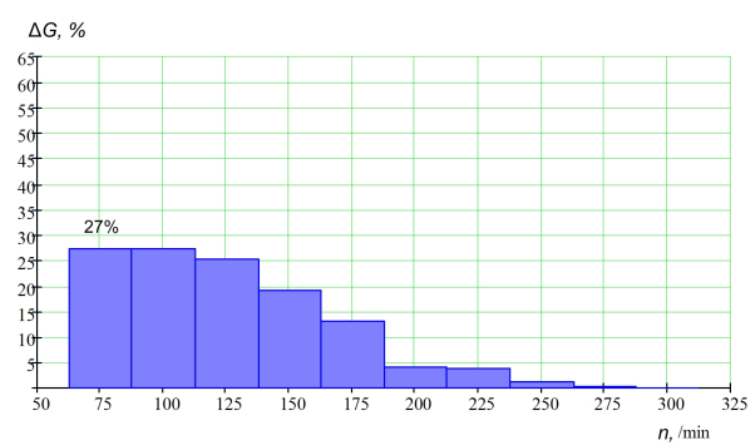

Figure 9. Absolute fuel consumption of ICE in UPS of 1000 $\mathrm{kW}$.

In absolute fuel consumption UPS with regulation frequency of DGI economical system without regulation by $25-27 \%$.

\section{UPS calculation of fuel economy considering at the SM control}

The above characteristics of specific and absolute fuel consumption rate have been obtained without taking into account SM excitation control. To enhance the economy of UPS, it is necessary to control the SM with respect to load power as related to the expression $[1,8,9]$

$$
i_{e x}=\sqrt{\frac{1+p_{1}^{2} x_{d}^{2}+2 p_{1} x_{d} \sqrt{1-\cos ^{2} \varphi}}{1+x_{d}^{2}+2 x_{d} \sqrt{1-\cos ^{2} \varphi}}}
$$

where $i_{\mathrm{ex}}=I_{\mathrm{ex}} / I_{\mathrm{ex} \text { nom }}, p_{1}=P_{1} / S_{\mathrm{NOM}}$.

As shown in graphs (Fig.10, 11), at the excitation control (Fig.10, curves 1,3), the fuel consumption rate increases by the range of light and average loads.

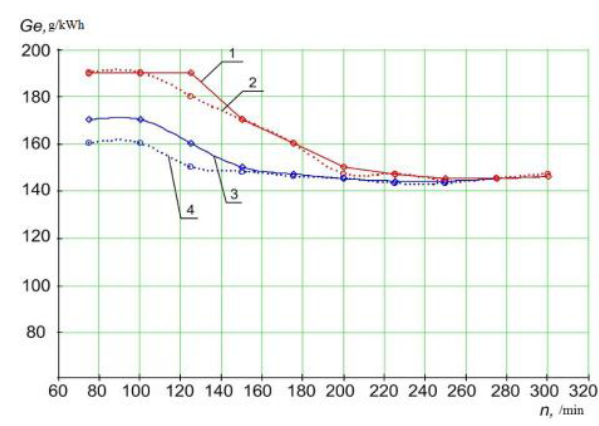

Figure 10. ICE average consumption rate of UPS power 1000 $\mathrm{kW}: 1,2$-without the speed regulation of DGI; 3,4 - with speed regulation of DGI; 1,3 - with regulation current excitation of SM; 2,4 - without regulation current excitation of SM.

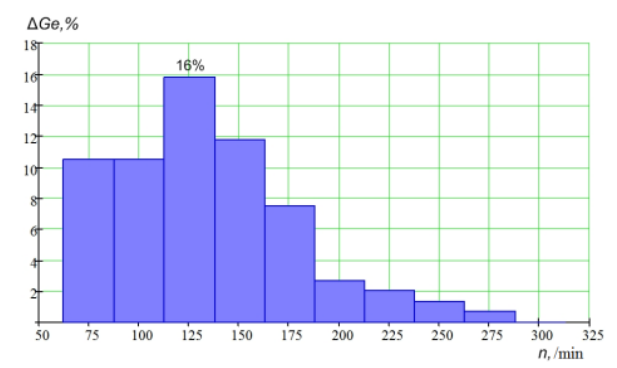

Figure 11. The ICE fuel consumption rate economy in UPS power $1000 \mathrm{~kW}$ with SM excitation control.
According to a multivariate characteristic, within the range of ICE light loads is displaces into the range of higher fuel consumption rate. The fuel calculation data are shown in fig. $12,13$.

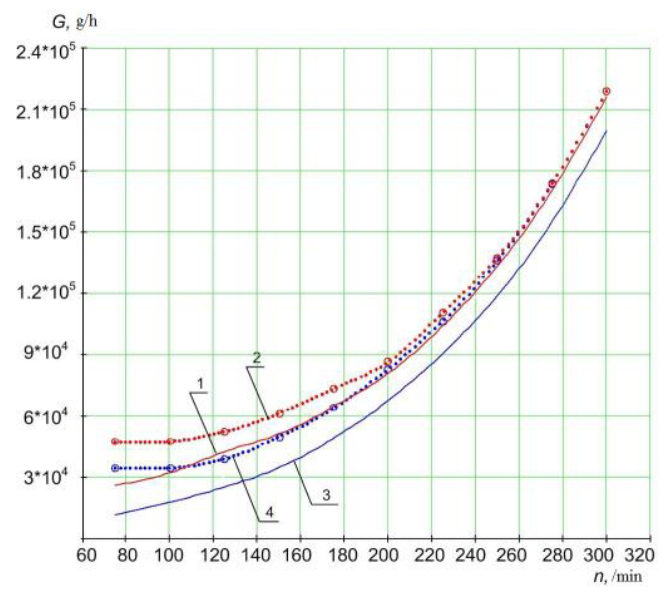

Figure 12. Absolute fuel rate consumption of ICE in UPS: 1,2without regulation speed of ICE, 3,4 - with speed regulation of ICE, 1,3 - with regulation current excitation of SM, 2,4 without with regulation current excitation of SM.

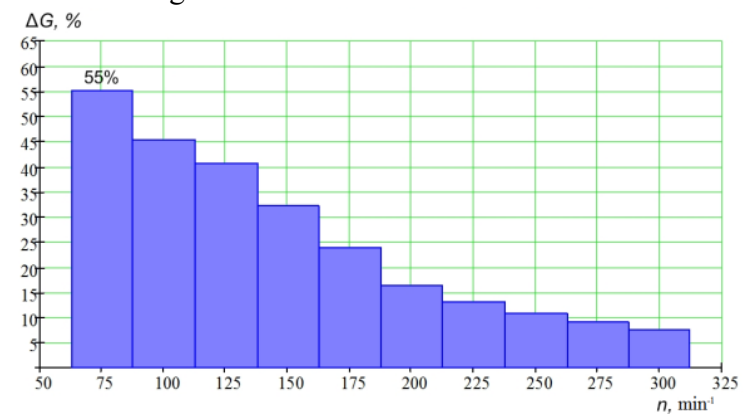

Figure 13. . Absolute fuel consumption of ICE in UPS power $1000 \mathrm{~kW}$ with regulation current excitation of SM.

\section{Conclusion}

Application UPS on the variable speed of ICE allows to efficiently economizing fuel consumption rate and reduces air emissions. Providing optimal mode of ICE in terms of fuel efficiency requires a new approach to the fuel supply control and can be implemented on modern management tools, including intelligent neural networktype control systems.

In the paper calculated the fuel efficiency of unified power station on the basis of a variable speed DGI power of $1000 \mathrm{~kW}$. On the basis of the calculation results obtained by the comparative characteristics of the specific and absolute fuel consumption for the two modes of operation: a speed control of rotation DGI, depending on the load and a constant frequency of rotation of the DGI. In UPS of $1000 \mathrm{~kW}$ fuel savings can be up to $31 \%$ in absolute consumption.

\section{Acknowledgment}

The research was performed with the support of the State Research Program (project № 8.2668.2014/K) on 
department «Electrical equipment, electric drive and automatics» of Nizhny Novgorod State Technical University n.a. R.E. Alekseev.

\section{References}

1. O.S. Khvatov, A.B. Daryenkov, I.S. Samoyavchev. Jekspluatacija morskogo transporta. The fuel profitability of unified electric power station of ship based on a explosion engine by alternating frequency rotation of shaf, 71, 47 (2013)

2. O.S. Khvatov, A.B. Daryenkov, I.S. Polyakov. Vestnik IGEU. Neural Network Algorithm of Control System of Fuel Supply of Frequency Rotation Diesel Generator Set, 3, 50 (2013)

3. O.S. Khvatov, A.B. Daryenkov. Promishlennaya energetika. A stand-alone diesel electric power station with a neural network economy mode cof neural network economy mode setting device, 12, 26 (2013)

4. O.S. Khvatov, A.B. Daryenkov. Elechtotechnika. Power plant based on a variable-speed diesel generator, 3, 28 (2014)
5. O.S. Khvatov, A.B. Dar'enkov, Russian Electrical Engineering. Power plant based on a variable-speed diesel generator, 85, 145 (2014)

6. A.B. Daryenkov, O.S. Khvatov, F.F. Yurlov, N.V. Usov. Vestnik of Astrakhan state technical university. Series: Marine engineering and technologies. Definition of economic efficiency of diesel electric power stations with alternating frequency of rotation of the shaft, 3, 64 (2014)

7. A.B. Daryenkov, O.S. Khvatov. News of the Tula state university. Technical sciences. Intelligent controls of highly effective the diesel-generator installation of variable frequency of rotation, 3, 126 (2010)

8. S.M. Dmitriev, V.V. Konratyev, O.S. Khvatov, A.B. Daryenkov, E.A. Chernov. Proceedings VII International Conference on Power Drives Systems. Intellectual servo-drive of fuel supply of a variable rotation speed stand-alone electric power station, 592 (2012)

9. O.S. Khvatov, A.B. Daryenkov, I.S. Samoyavchev. Proceedings VIII International Conference on Power Drives Systems. High-efficiency electric propulsion system of a stand-alone object, 2, 396 (2014) 